\title{
Fertilization and activation currents in bovine oocytes
}

\author{
E. Tosti ${ }^{1}$, R. Boni ${ }^{2}$ and A. Cuomo ${ }^{1}$ \\ ${ }^{1}$ Cell Biology Unit, Stazione Zoologica 'Anton Dohrn', Villa Comunale, 80121 Napoli, Italy; and \\ ${ }^{2}$ Department of Animal Science, University of Basilicata, Via N. Sauro, 85, 85100 Potenza, Italy
}

\begin{abstract}
One of the first events that occurs at fertilization is a transient modification of the electrical properties of the oocyte plasma membrane. The whole-cell voltage clamp technique was used to demonstrate an outward ion current and a hyperpolarization of the plasma membrane after fertilization in bovine oocytes. These electrical events, together with measurement of internal calcium concentrations, were also recorded after injection with sperm factor and exposure to parthenogenetic activators, such as $\mathrm{Ca}^{2+}$ ionophore, ethanol and thapsigargin. Experiments were carried out simultaneously in immature and in vitro matured oocytes. Significant differences were recorded in the activation current and hyperpolarization among oocyte activators and between immature and matured oocytes. However, outward ion current and $\mathrm{Ca}^{2+}$ release showed similar dynamics. The injection of the calcium chelator EGTA completely abolished both ion current and hyperpolarization, indicating that these electrical events
\end{abstract}

are calcium dependent. Addition of specific calcium releasers, such as 1,4,5-inositol trisphosphate $\left(\mathrm{IP}_{3}\right)$ and caffeine, triggered ion activation current and hyperpolarization indicating that $\mathrm{IP}_{3}$ and ryanodine receptors are active in both immature and matured oocytes. Different ion channel inhibitors were used to characterize the channels underlying outward currents. Only addition of rlberiotoxin caused a complete inhibition of the current, indicating the involvement of high conductance $\mathrm{Ca}^{2+}$ activated $\mathrm{K}^{+}$channels in generating activation current. In conclusion, these findings provide evidence that bovine oocyte activation is associated with $\mathrm{Ca}^{2+}$-dependent electrical events. Oocytes have the potential to react to different activators even when immature; however, oocyte maturation seems to increase sensitivity to physiological activators, such as spermatozoa and sperm factor, and chemicals, such as ethanol.

\section{Introduction}

An early event that occurs at fertilization is the change in the oocyte plasma membrane potential, which transiently depolarizes in ascidians and sea urchins (Dale and De Felice, 1984; De Simone et al., 1998), and hyperpolarizes in some mammalian species (Miyazaki, 1988; Gianaroli et al., 1994). The whole-cell voltage clamp technique has been used to demonstrate that these electrical events are due to the gating of ion channels generating flux of ions through the plasma membrane of the fertilized oocyte (for a review, see Dale, 1994). The sperm-activated ion currents are non-specific in marine invertebrates (Dale and De Felice, 1984; De Simone et al., 1998) and calciumactivated potassium currents in hamsters and humans (Miyazaki and Igusa, 1982; Dale et al., 1996).

Another universal event that occurs at fertilization is the massive release of calcium that traverses the oocyte in a wave (for reviews, see Swann and Ozil, 1994; Stricker, 1999). In Xenopus laevis and the sea urchin, a single increase in calcium occurs at oocyte activation (Busa and Nuccitelli, 1985; Gillot and Whitaker, 1993), whereas in ascidian and mammalian oocytes, repetitive calcium

Email: tosti@szn.it oscillations are reported up to extrusion of the second polar body (Russo et al., 1996; Yoshida et al., 1998) and pronuclear formation (Stricker, 1999; Swann and Parrington, 1999). The origin of these increases in calcium may be attributed to an influx through the plasma membrane or to an internal release from calcium stores. In bovine oocytes, Tosti et al. (2000) reported a decrease in plasma membrane $\mathrm{Ca}^{2+}$ currents during meiotic progression and Boni et al. (2002) reported a prevalence of $\mathrm{Ca}^{2+}$ stores in immature compared with in vitro matured oocytes. To date, a clear relationship at fertilization between electrical currents and $\mathrm{Ca}^{2+}$ release has not been demonstrated in mammals.

Oocyte activation is artificially induced by: (i) agents, such as the calcium ionophore that increase calcium content (Steinhardt and Epel, 1974; Steinhardt et al., 1974) and thapsigargin (Petr et al., 2000); (ii) ethanol (Nagai, 1987); (iii) inhibitors of protein synthesis and protein phosphorylation (Presicce and Yang, 1994; Liu et al., 1998); and (iv) electrical pulses (Collas et al., 1993). In bovine oocytes, activation by $\mathrm{Ca}^{2+}$ ionophore and ethanol results in a wide range of parthenogenetic development from cleavage up to blastocyst formation (Shi et al., 1993; Presicce and Yang, 1994). It has been suggested that activation is mediated by an increase in $\mathrm{Ca}^{2+}$ that in turn leads to the exit from the second meiotic block via the inactivation of the cytostatic factor and consequently the 
mitotic promoting factor (for a review, see Parrish et al., 1992). Calcium mobilization seems to come from intracellular stores in most of the species studied; however, external calcium has also been demonstrated to replenish the stores for the continuation of calcium signals (Stricker, 1999). Studies on parthenogenesis represent a crucial step for understanding the basic mechanisms underlying oocyte activation and embryo development. Artificial activation and fertilization seem to share common mechanisms in many animal species, as artificial stimuli mimic both electrical responses and calcium oscillations observed at fertilization (Nuccitelli, 1980; Schlichter and Elisson, 1981; Swann, 1990; Dale et al., 1996). Early studies by Eusebi and Siracusa (1983) showed that a variety of different stimuli trigger parthenogenetic development in mice and hamsters; however, the electrical events generated were not driven by common ionic mechanisms or by the classical activation potential. A clear understanding of oocyte activation mechanisms is required for assisted reproductive technologies, such as intracytoplasmic sperm injection (ICSI), nuclear transfer and cloning in cattle. Despite the large number of studies on oocyte activation, little is known about the electrical events induced by different activators or the nature of the ion channels responsible for this.

The aim of the present study was to investigate the first electrical modifications that occur in bovine oocytes after activation and to relate these modifications to $\mathrm{Ca}^{2+}$ dynamics. This analysis was carried out in both immature and in vitro matured oocytes to define the origin of such mechanisms.

\section{Materials and Methods}

\section{Materials}

If not otherwise stated all chemicals were purchased from Sigma Chemical Co. (St Louis, MO) and were of tissue culture grade where appropriate.

\section{Oocyte source and in vitro maturation}

Ovaries from slaughtered cows were collected from the abattoir and transported in a thermal bag at $30-35^{\circ} \mathrm{C}$ to the laboratory within $3-4 \mathrm{~h}$ of collection. The laboratory temperature was $30^{\circ} \mathrm{C}$. Immature oocytes were collected from follicles of $2-8 \mathrm{~mm}$ in diameter by an $18 \mathrm{G}$ needle under controlled pressure (50-70 $\mathrm{mmHg}$ ). Cumulus-oocyte complexes (COC) were isolated from the follicular fluid and washed three times with washing medium (TCM-199 supplemented with $0.1 \%(\mathrm{w} / \mathrm{v})$ polyvinyl alcohol and 10 mol Hepes $\left.~^{-1}\right)$. The COC were then transferred into maturation medium (TCM-199 supplemented with 10\% (v/v) fetal calf serum, 10.0 iu $\mathrm{LH} \mathrm{ml}^{-1}, 0.1$ iu FSH ml-1 and $1 \mu \mathrm{g}$ oestradiol $\left.\mathrm{ml}^{-1}\right)(40 \mu \mathrm{l}$ per COC) and kept in an incubator at $39^{\circ} \mathrm{C}$ in $5 \%(\mathrm{v} / \mathrm{v}) \mathrm{CO}_{2}$ humidified air for $24 \mathrm{~h}$. At the time of each experimental session, immature and mature oocytes were freed from the cumulus cells by vortexing for $3 \mathrm{~min}$ in washing medium. The zona pellucida was removed after incubation for 1.0-1.5 $\mathrm{min}$ in $0.5 \%(\mathrm{w} / \mathrm{v})$ protease dissolved in washing medium. The zona pellucidafree oocytes were then incubated for $10 \mathrm{~min}$ at $39^{\circ} \mathrm{C}$ in TCM-199 supplemented with $10 \%$ (v/v) fetal calf serum and 10 mol Hepes $\mathrm{I}^{-1}$ and, finally, transferred in Fert-Tyrode's albumin lactate pyruvate (TALP) (Parrish et al., 1986) medium supplemented with Hepes (wash-TALP) and kept in an incubator until the electrical recording or calcium measurement was performed.

Immature COC were selected on the basis of morphology (De Loos et al., 1989). In brief, at least three layers of cumulus cells entirely surrounded the oocytes, which were assumed to be at the germinal vesicle stage up to $4 \mathrm{~h}$ after their removal from the enclosed follicle.

Oocytes matured in vitro were obtained at the end of the maturation period ( $24 \mathrm{~h}$ ) and selected on the basis of the presence of a clear polar body and a homogeneous cytoplasm. For each experiment, a batch of ten oocytes was fixed in acetic-ethanol (1:3) solution and after $24 \mathrm{~h}$ stained with $1 \%(\mathrm{w} / \mathrm{v})$ lacmoid solution to determine the number that had reached metaphase II (MII). The proportion of oocytes at MII ranged between $80 \%$ and $100 \%$ throughout the entire experimental period.

\section{Electrophysiology}

Electrical recording was performed at $39^{\circ} \mathrm{C}$ on oocytes in either the immature or in vitro matured stages. Zona pellucida-free oocytes were placed in a recording chamber containing $200 \mu \mathrm{l}$ wash-TALP. Oocytes were voltageclamped using standard techniques. Patch pipettes of $10 \mathrm{M} \Omega$ resistance and $1-2 \mu \mathrm{m}$ in tip diameter were filled with an intracellular-like solution (ICS) containing $70 \mathrm{mmol}$ $\mathrm{KCl} \mathrm{I}^{-1}, 7 \mathrm{mmol} \mathrm{NaCl} \mathrm{I}^{-1}, 10 \mathrm{mmol}$ EGTA I-1, $10 \mathrm{mmol}$ Hepes $\mathrm{I}^{-1}$, pH 7.4, and 280 mOsm. After obtaining a giga $\Omega$ seal, the pipette voltage was set to the desired negative potential and the patch ruptured. Observation of a stable negative resting potential signalled access to the cytosol. The permeabilization of the plasma membrane after the oocyte activation was verified by applying depolarizing and hyperpolarizing voltage steps of $10 \mathrm{mV}$ and $500 \mathrm{~ms}$ before and at the peak current to generate the voltage-dependent currents. All microinjections were performed in the patch clamp configuration with an Eppendorf transjector (Hamburg) with an estimated injection volume corresponding to $1-2 \%$ $(\mathrm{v} / \mathrm{v})$ of the oocyte. All electrical traces were recorded on a List EP7 amplifier and data were stored on a VCR tape for subsequent analysis.

\section{$\left[\mathrm{Ca}^{2+}\right]_{i}$ determinations}

Immature and in vitro matured zona pellucida-free oocytes were placed in a recording chamber containing $2 \mathrm{ml}$ of either wash-TALP medium or $\mathrm{Ca}^{2+}$-free TALP medium supplemented with $1 \mathrm{mmol}^{\mathrm{EGTA}} \mathrm{I}^{-1}$ at $39^{\circ} \mathrm{C}$ and injected using the standard techniques described above with the fluorescence dye calcium green dextran $\left(M_{r} 10000\right)$ (Molecular Probes, Leiden). This dye was diluted in ICS with 
a concentration in the pipette of $0.5 \mathrm{mmol} \mathrm{I}^{-1}$. $\mathrm{Ca}^{2+}$ stores were evoked by the addition of spermatozoa, $5 \mu \mathrm{mol}$ $\mathrm{Ca}^{2+}$ ionophore $\mathrm{I}^{-1}, 7 \%(\mathrm{v} / \mathrm{v})$ ethanol, $10 \mu \mathrm{mol}$ thapsigargin $\mathrm{I}^{-1}, 20 \mathrm{mmol}$ caffeine $\mathrm{I}^{-1}$ and by injecting $5 \mu \mathrm{mol} 1,4,5$ inositoltrisphosphate $\left(\mathrm{IP}_{3}\right) \mathrm{I}^{-1}$ and sperm factor with a subsequent injection. $\mathrm{Ca}^{2+}$ values were monitored using a computer-controlled photo-multiplier system. In brief, a digital video microscopy system on a Zeiss (Göttingen) Axiovert 135 microscope and an ORCA-100 Hamamatsu (Hamamatsu Photonics Italia, Arese) 12-bit digital camera were controlled by a Macintosh G3 workstation. This computer was used to control the microscopy system and to perform all the image acquisitions and elaborations using the Openlab program (Improvision, Coventry). The fluorescent signals were corrected for variation in dye concentration by normalizing fluorescence $(F)$ against baseline fluorescence $(F O)$, to obtain reliable information about transient $\mathrm{Ca}^{2+}$ changes from baseline values $(F-F O / F O)$ and to exclude variations in fluorescence intensity by different volumes of injected dye.

\section{In vitro fertilization}

Frozen straws of semen from bulls, previously tested by IVF procedures, were thawed in water at $30^{\circ} \mathrm{C}$ for $30 \mathrm{~s}$. The spermatozoa were layered on to a discontinuous (90/40: v/v) Percoll gradient and centrifuged at $180 \mathrm{~g}$ for $30 \mathrm{~min}$. The resultant pellet of spermatozoa was washed twice in sperm-TALP medium by centrifugation at $180 \mathrm{~g}$ for $5 \mathrm{~min}$. Finally, the preparation was adjusted to approximately $10 \times 10^{6}$ spermatozoa $\mathrm{ml}^{-1}$ and an equal volume of $200 \mu \mathrm{g}$ heparin $\mathrm{ml}^{-1}$ in sperm-TALP medium was added. After $3 \mathrm{~h}$ of incubation at $39^{\circ} \mathrm{C}$, the sperm preparation was added to zona pellucida-free in vitro matured patch-clamped oocytes within a $2 \mathrm{ml}$ wash-TALP bath. During the time course, $>50$ control oocytes were fertilized and the resulting embryos were cultured according to Boni et al. (2002). The cleavage and blastocyst rates were always $>75 \%$ and $>20 \%$, respectively.

\section{Sperm factor}

Bovine sperm factor was prepared according to Swann (1990) with some modifications. In brief, 18 frozen semen straws from eight different bulls, previously tested by IVF procedures, were thawed in water at $30^{\circ} \mathrm{C}$. The spermatozoa were layered on to a discontinuous (90/40: v/v) Percoll gradient and centrifuged at $180 \mathrm{~g}$ for $30 \mathrm{~min}$. The resultant pellet of spermatozoa was washed twice in sperm-TALP medium by centrifugation at $180 \mathrm{~g}$ for $5 \mathrm{~min}$. Finally, the pellet was resuspended in $2 \mathrm{ml}$ of intracellular-like medium (120 mmol KCl l-1, 20 mmol Hepes $\mathrm{I}^{-1}$, $500 \mu \mathrm{mol}$ EGTA I-1, $10 \mathrm{mmol}$ glycerophosphate $\mathrm{I}^{-1}$, $1 \mathrm{mmol}$ dithiothreitol $\mathrm{I}^{-1}$, $200 \mu \mathrm{mol}$ phenylmethansulfonyl fluoride $\mathrm{I}^{-1}, \mathrm{pH} 7.5$ and $300 \mathrm{mOsm}$ ) and mechanically homogenized for $20 \mathrm{~min}$ on ice. The cell rupture was monitored under a microscope. The resulting homogenate was ultracentrifuged at $180000 \mathrm{~g}$ for $120 \mathrm{~min}$. The supernatant was filtered through a $0.2 \mu \mathrm{m}$ pore-size filter, separated into aliquots and stored at $-80^{\circ} \mathrm{C}$ until use. The sperm factor was injected into the oocytes as mentioned above. The sperm equivalent injected was estimated to be two to four.

\section{Oocyte activation}

Immature and in vitro matured bovine oocytes were exposed to $\mathrm{Ca}^{2+}$ ionophore $\mathrm{A} 23187$ (from $100 \mathrm{nmol} \mathrm{I}^{-1}$ to $\left.5 \mu \mathrm{mol} \mathrm{I}{ }^{-1}\right)$ or $7 \%(\mathrm{v} / \mathrm{v})$ ethanol. $\mathrm{Ca}^{2+}$ dependence of the ion currents triggered by these substances was tested by injecting the oocytes with the $\mathrm{Ca}^{2+}$ chelator EGTA at final concentration of $1 \mu \mathrm{mol} \mathrm{I}-1$ and loading for 10 min before exposure to activators. $\mathrm{IP}_{3}$ and caffeine, which act through the $\mathrm{IP}_{3}$ and ryanodine calcium release receptors were used to test further the calcium dependence of the ion activation current. $\mathrm{IP}_{3}$ was dissolved in ICS and microinjected at a

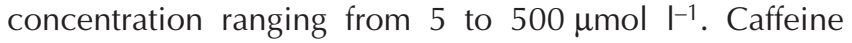
was dissolved in Fert-TALP medium at $200 \mathrm{mmol} \mathrm{I}^{-1}$ by heating at $70^{\circ} \mathrm{C}$ (Patel et al., 1997) and added to the recording bath at a final concentration of $20 \mathrm{mmol} \mathrm{I}^{-1}$. The effect of $\mathrm{IP}_{3}$ and caffeine was evaluated by pre-loading the oocytes with specific inhibitors of the receptors, such as heparin $\left(1 \mathrm{mg} \mathrm{ml}^{-1}\right)$ and procaine $(50 \mu \mathrm{mol} \mathrm{I}-1)$.

Finally, thapsigargin, a potent inhibitor of sarco/ endoplasmic reticulum $\mathrm{Ca}^{2+} \mathrm{ATPase}$, was added to the bath at a final concentration of $10 \mu \mathrm{mol} \mathrm{I}^{-1}$.

\section{Pharmacological studies}

The nature of the channels generating the ionophoreinduced current was determined by incubating oocytes with some ion channel inhibitors: (i) inhibitors of voltagegated $\mathrm{K}^{+}$channels, such as tetraethylammonium chloride (TEA) (5-10 mmol $\mathrm{I}^{-1}$ for $10-30 \mathrm{~min}$ ) and DendrotoxinK (from $25 \mathrm{nmol} \mathrm{I}^{-1}$ to $500 \mu \mathrm{mol} \mathrm{^{-1 }}$ for $5 \mathrm{~min}$ ); (ii) inhibitors of high, low and medium conductance $\mathrm{Ca}^{2+}$-activated $\mathrm{K}^{+}$ channels, such as rlberiotoxin (from $100 \mathrm{nmol} \mathrm{\textrm {I } ^ { - 1 }}$ to $2.5 \mu \mathrm{mol} \mathrm{I}^{-1}$ for $\left.2-5 \mathrm{~min}\right)$, Apamin ( $1 \mu \mathrm{mol} \mathrm{I} \mathrm{I}^{-1}$ for $\left.2-5 \mathrm{~min}\right)$ and rCharibdotoxin (10-100 $\mathrm{nmol} \mathrm{I}^{-1}$ for 2-5 min), respectively; (iii) inhibitors of $\mathrm{Cl}^{-}$channels, such as Clorotoxin

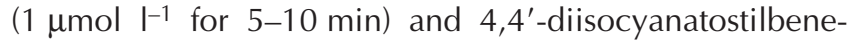
$2,2^{\prime}$-disulphonic acid (DIDS) (from $100 \mu \mathrm{mol} \mathrm{I}^{-1}$ to $1 \mathrm{mmol} \mathrm{I}^{-1}$ for 2-5 min). All the above toxins were purchased from Alomone Labs (Jerusalem).

\section{Statistical analysis}

If not otherwise stated, a total of ten oocytes at each stage, distributed within at least three replications, was submitted for the following electrophysiological, calcium and pharmacological determinations. Differences between peak values of electrical currents and calcium dynamics generated by spermatozoa, sperm factor and oocyte activators were tested by ANOVA of the General Linear Model (GLM) procedure (SAS, 1988). Hyperpolarization was evaluated by normalizing the more negative resting potential observed at the peak current against the baseline resting potential and analysed by ANOVA. 


\section{Results}

\section{Electrical events}

Oocytes matured in vitro were whole-cell voltage clamped at $-30 \mathrm{mV}$. After the addition of heparincapacitated bovine spermatozoa to the oocytes matured in vitro, a bell-shaped outward ion activation current was recorded $313 \pm 80 \mathrm{~s}$ after the addition of spermatozoa. The time interval between the beginning of the current and its peak (PR) was $337 \pm 35$ s (Figs 1a and 2a). This fertilization current was accompanied by a progressive hyperpolarization of the plasma membrane resting potential that reached a maximum at the peak current (Fig. 2b) and progressively repolarized up to the resting values. This pattern was then used as a reference for the study of the various activation mechanisms examined. Microinjection of the bovine sperm factor soluble fraction generated an immediate ion activation current and hyperpolarization (Figs $1 \mathrm{~b}$ and 2a,b). However, the dynamics of these electrical events were different from those evoked by the spermatozoon; sperm factor induced an ion activation current characterized by a faster slope than the spermatozoon (Fig. 1a,b), but with lower (2.3 versus $4.4 ; P<0.01)$ hyperpolarization and higher ion activation current peak (504 versus $334 \mathrm{pA} ; P<0.05$ ) values (Fig. 2b).

All oocyte activators evoked electrical responses with specific dynamics. However, on the basis of their short PR none of these substances mimicked the sperm-induced ion activation current. Differences in peak values of these ion activation current and hyperpolarization were found among these activators (Fig. 2a,b). $\mathrm{Ca}^{2+}$ ionophore elicited the highest response at $5 \mu \mathrm{mol} \mathrm{I}^{-1}$ and a high response was maintained up to $100 \mathrm{nmol} \mathrm{I}^{-1}$ (data not shown).

Activation currents and hyperpolarization were also generated in the immature oocytes but with different dynamics from those of matured oocytes. The sperm penetration triggered a lower electrical current $(P<0.01)$ but of a similar duration to that of matured oocytes. This current was characterized by repetitive oscillations. Activation peak current induced by the sperm factor was significantly $(P<0.01)$ lower in immature oocytes than in oocytes matured in vitro (Fig. 2a); however, this difference was not significant in relation to hyperpolarization values (Fig. 2b). In immature oocytes, ethanol generated a lower $(P<0.01)$ ion activation current and hyperpolarization and a longer PR $(148 \pm 92 \mathrm{~s}$ versus $40 \pm 22 \mathrm{~s}, P<0.01)$ than in matured oocytes (Fig. 1c, 2a,b). In the case of $\mathrm{Ca}^{2+}$ ionophore, the amplitude of the ion activation current was significantly $(P<0.01)$ higher in the immature than in matured oocytes and showed an increased initial slope rate of the current (Figs 1d, 2a). In addition, in immature oocytes, thapsigargin showed a higher ion activation current $(P<0.05)$ and hyperpolarization $(P<0.01)$ than in matured oocytes (Figs 1e and 2a,b).

Exclusively for the $\mathrm{Ca}^{2+}$ ionophore treatment, ramps of $10 \mathrm{mV}$ depolarizing and hyperpolarizing steps were applied from the voltage clamp of $-30 \mathrm{mV}$, which generated a series of whole cell currents. $I(V)$ curves were linear (data not shown). At the peak current, an increase of $17 \mathrm{nS}$ $(2.3 \pm 0.6$-fold $)$ and $9.1 \mathrm{nS}(1.6 \pm 0.3$-fold $)$ steady state conductance was recorded in immature and in matured oocytes, respectively.

Controls performed at the beginning of each experiment using sham injections or the addition of the activator solvents at the concentrations used did not elicit any electrical event. In most of the electrical recordings, the agonist-induced activation ion currents were preceded by a transient inward current, accompanied by a depolarization of the resting potential. In immature oocytes the amplitude of this current was significantly higher compared with that of matured oocytes $(146 \pm 112 \mathrm{pA}$ versus $55 \pm 38 \mathrm{pA}$, $P<0.05)$. At times, this event did not occur, probably masked by the negative shift. The use of a $\mathrm{Ca}^{2+}$ free medium supplemented with $1 \mathrm{mmol}$ EGTA $\mathrm{I}^{-1}$ inhibited these electrical events after $\mathrm{Ca}^{2+}$ ionophore treatment.

\section{Effect of calcium on electrical events}

Oocytes were injected with EGTA at a final concentration of $1 \mathrm{mmol} \mathrm{I}^{-1}$, to investigate whether intracellular calcium is involved in the fertilization and activation currents in bovine oocytes. The subsequent addition of $5 \mu \mathrm{mol} \mathrm{Ca}^{2+}$ ionophore $\mathrm{I}^{-1}$ did not elicit an activation current or hyperpolarization in either immature or matured oocytes. Occasionally, after EGTA injection, a small inward current and a depolarization indicating a capacitative mechanism (Clapham, 1995) induced by depletion of the intracellular stores were observed.

Specific calcium releasers, such as $\mathrm{IP}_{3}$ and caffeine, also triggered activation current and hyperpolarization. Microinjection of $\mathrm{IP}_{3}\left(5\right.$ and $500 \mu \mathrm{mol} \mathrm{I}^{-1}$ ) induced a marked electrical response (Figs $1 \mathrm{f}$ and 2a,b). This current was recorded even when a lower $\mathrm{IP}_{3}$ dose $\left(5 \mu \mathrm{mol} \mathrm{I}^{-1}\right)$ was used and was characterized by high slope current. A significant ion activation current difference $(P<0.01)$ between immature and matured oocytes was found at both $5 \mu \mathrm{mol}$

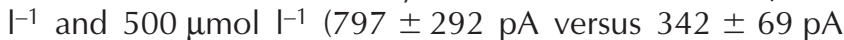
and $1230 \pm 507 \mathrm{pA}$ versus $847 \pm 419 \mathrm{pA}$, respectively). Caffeine (20 mmol $\mathrm{I}^{-1}$ ) also generated ion activation current and hyperpolarization (Figs $1 \mathrm{~g}$ and $2 \mathrm{a}, \mathrm{b}$ ) with higher values $(P<0.01)$ in immature oocytes.

The mechanisms underlying the $\mathrm{Ca}^{2+}$ release mobilized by $\mathrm{IP}_{3}$ and caffeine were investigated by using antagonists of calcium release. The $\mathrm{IP}_{3}$ generated current was abolished when oocytes were pre-injected with heparin. A previous injection of procaine resulted in the inhibition of caffeineinduced ion activation current and hyperpolarization. The addition of $\mathrm{Ca}^{2+}$ ionophore to heparin and procaine preloaded oocytes did not inhibit these electrical events.

Immediately after the closure of activation currents, the addition of $\mathrm{Ca}^{2+}$ ionophore to the same oocytes $(n=5$ for each agonist used) did not cause any or caused minimal additional electrical events. Oocyte activation in $\mathrm{Ca}^{2+}$-free medium did not affect either activation current or hyperpolarization. 

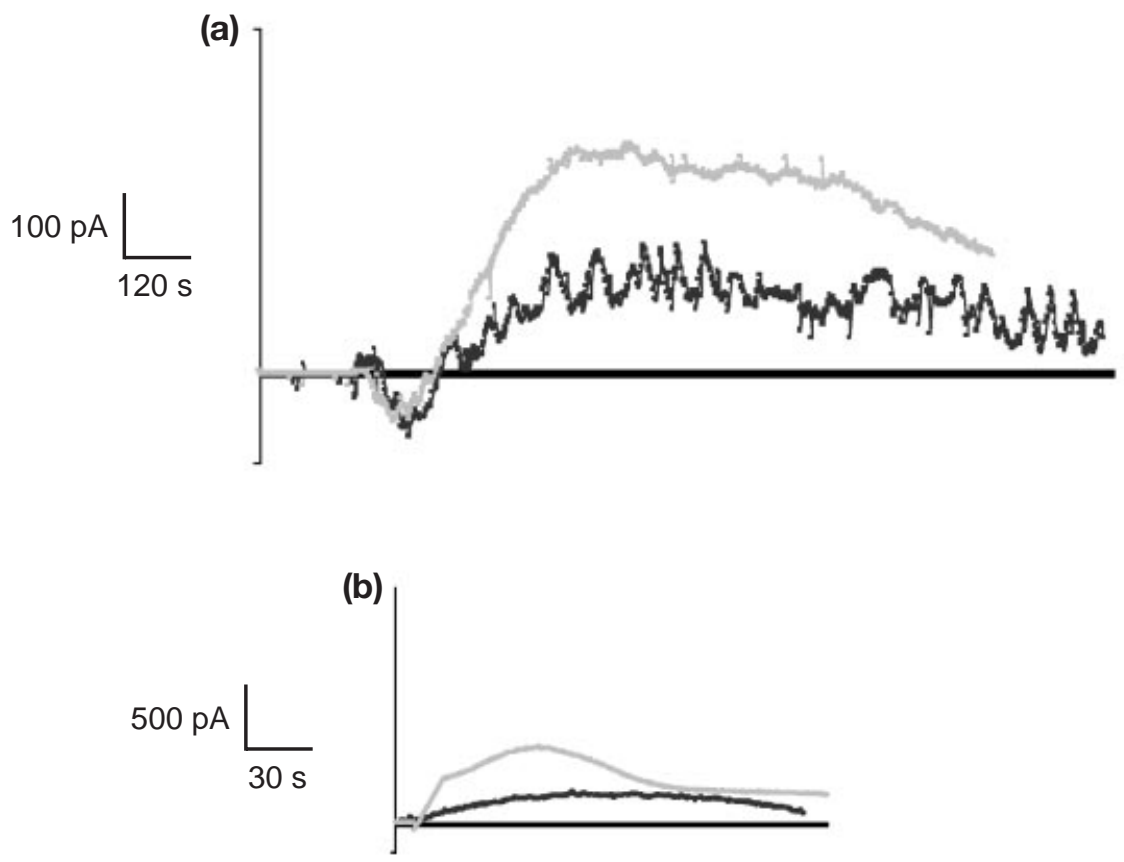

(c)

(d)

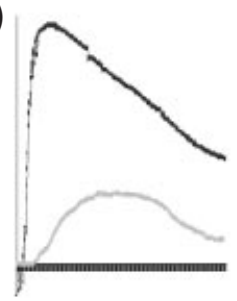

(e)

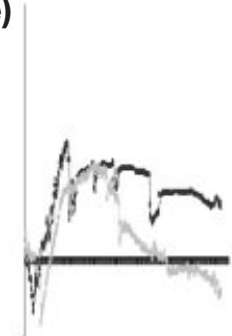

(f)

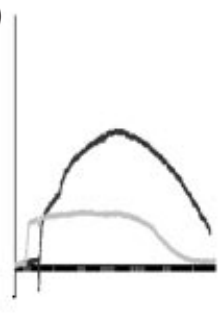

(g)

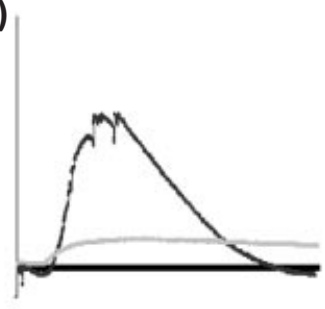

Fig. 1. Typical traces of the activation current intensity in immature (black trace) and in vitro matured (grey trace) bovine oocytes that were whole-cell voltage clamped at $-30 \mathrm{mV}$. The bovine oocytes were (a) exposed to bovine spermatozoa, (b) injected with bovine sperm factor, (c) exposed to $7 \%(\mathrm{v} / \mathrm{v})$ ethanol, (d) exposed to $5 \mu \mathrm{mol} \mathrm{Ca}^{2+}$ ionophore, $\mathrm{A} 23187 \mathrm{I}^{-1}$, (e) injected with

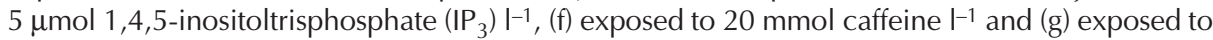
$10 \mu \mathrm{mol}$ thapsigargin $\mathrm{I}^{-1}$. Top scale bar refers to (a) and the lower scale bar refers to (b-g).

\section{Calcium release}

The patterns of the first $\mathrm{Ca}^{2+}$ transient release after exposure of the oocytes to the ion activation current inducers (Fig. 3) reflect the electrical activation curves and confirm higher values in immature oocytes after exposure to $\mathrm{Ca}^{2+}$ ionophore, thapsigargin, $\mathbb{I P}_{3}$ and caffeine (Fig. 3d-g).
However, spermatozoa, sperm factor and ethanol showed higher values in oocytes matured in vitro (Fig. 3a,b,c). Calcium curves were longer and more persistent than the electrical curves (Figs 1 and 3). $\mathbf{I P}_{3}$ injection resulted in the highest peak in both immature and matured oocytes; in immature oocytes the peak occurred within $3 \mathrm{~s}$ after the 

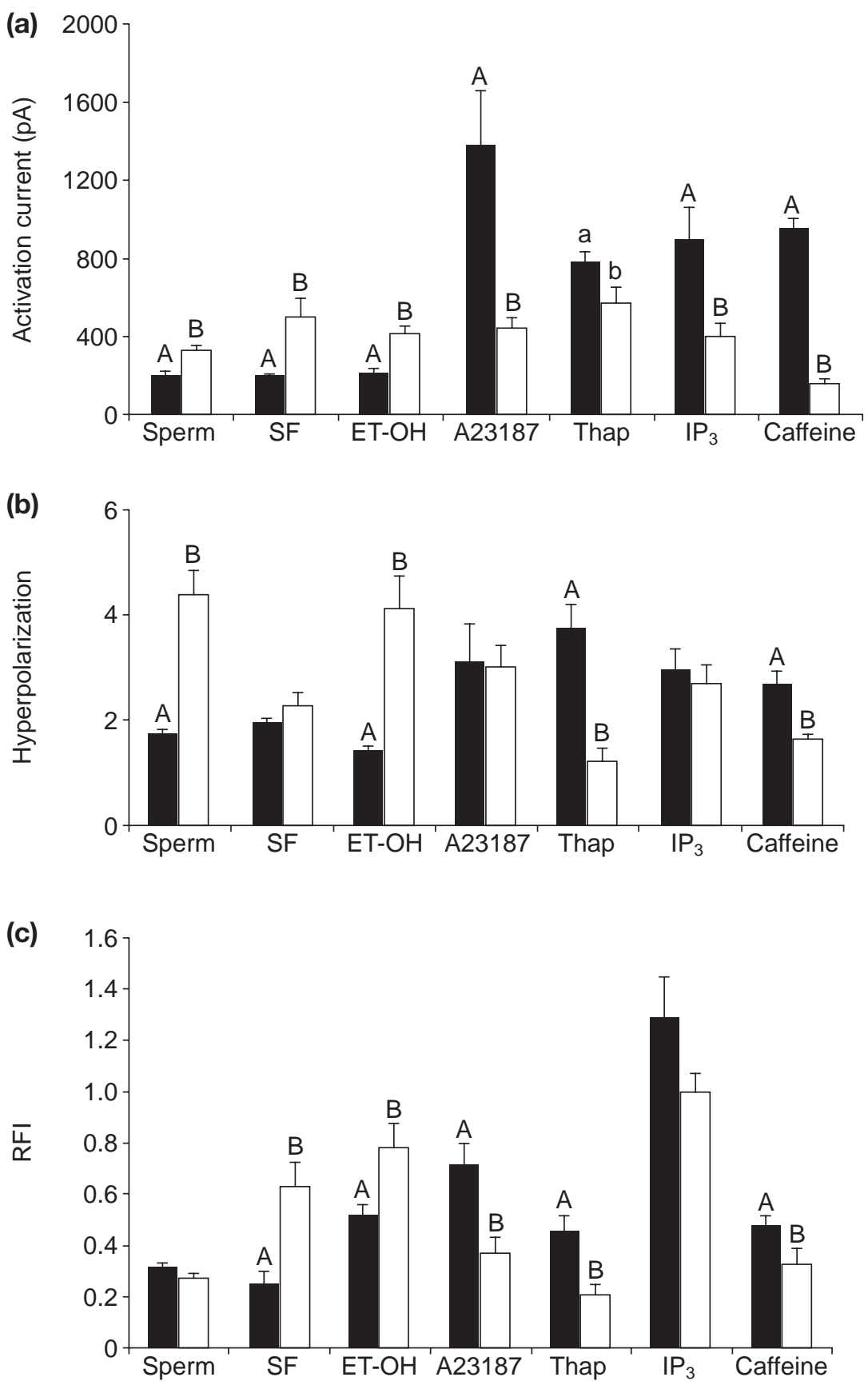

Fig. 2. (a) Activation current intensities (mean \pm SEM) and (b) hyperpolarizations (mean \pm SEM) expressed as the ratio of the peak $(\mathrm{mV})$ and the resting value $(\mathrm{mV})$ recorded in immature ( $\square$ ) and in vitro matured $(\square)$ bovine oocytes that were voltage clamped at $-30 \mathrm{mV}$ and exposed to bovine spermatozoa (sperm), $7 \%(\mathrm{v} / \mathrm{v})$ ethanol (ET-OH), $5 \mu \mathrm{mol} \mathrm{Ca}{ }^{2+}$ ionophore (A23187) $\mathrm{I}^{-1}, 20 \mathrm{mmol}^{-1}$ caffeine $\mathrm{I}^{-1}$, $10 \mu \mathrm{mol}$ thapsigargin (Thap) $\mathrm{I}^{-1}$ or injected with bovine sperm factor (SF) and $5 \mu \mathrm{mol}$ 1,4,5-inositoltrisphosphate $\left(\mathrm{IP}_{3}\right)^{-1}$. (c) Intracellular calcium variations (mean \pm SEM) in immature $(\boldsymbol{\square})$ and in vitro matured $(\square)$ bovine oocytes injected with calcium green dextran $\left(10000 \mathrm{M}_{r}\right)$ after exposure to bovine spermatozoa (sperm), 7\% (v/v) ethanol (ET-OH), $5 \mu \mathrm{mol} \mathrm{Ca}{ }^{2+}$ ionophore (A23187) $\mathrm{I}^{-1}, 20 \mathrm{mmol}$ caffeine $\mathrm{I}^{-1}$ and $10 \mu \mathrm{mol}$ thapsigargin (Thap) $\mathrm{I}^{-1}$ or injection with bovine sperm factor (SF) and $5 \mu \mathrm{mol}$ 1,4,5-inositoltrisphosphate $\left(\mathrm{IP}_{3}\right) \mathrm{I}^{-1}$. Data were expressed as variations of the relative fluorescence intensity (RFI). Significant difference between immature and in vitro matured bovine oocytes: ${ }^{\mathrm{A}, \mathrm{B}} P<0.01 ; \mathrm{a}, \mathrm{b} P<0.05$. 
(a)

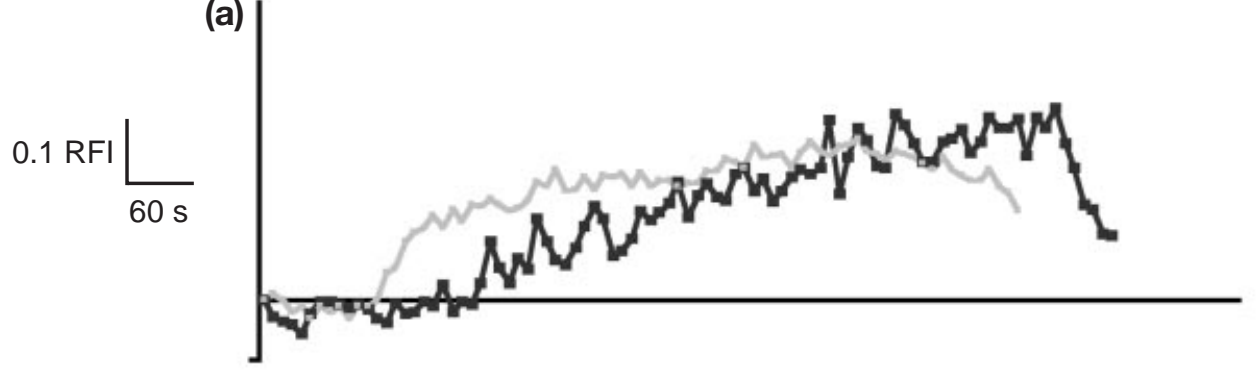

(b)

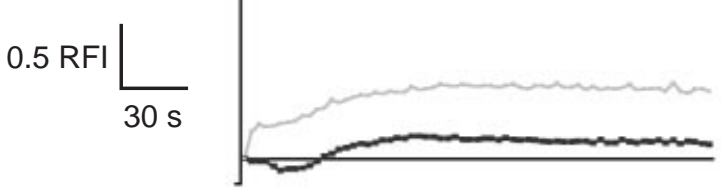

(c)

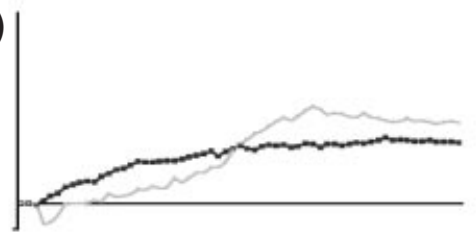

(d)

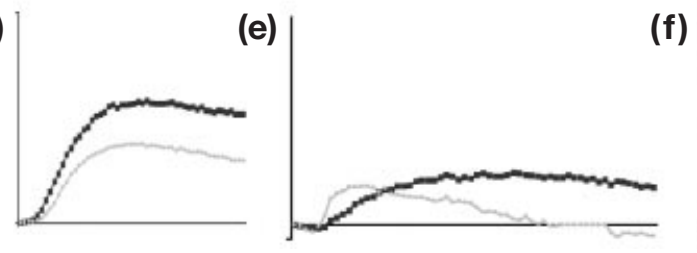

(f)

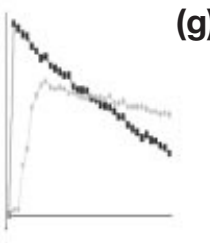

(g)

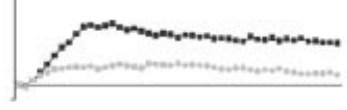

Fig. 3. Typical traces of the intracellular calcium release response in immature (black trace) and in vitro matured (grey trace) bovine oocytes that were pre-injected with the fluorescence dye, calcium green dextran 10000 . An increase in calcium was elicited by (a) exposure to bovine spermatozoa, (b) injection with bovine sperm factor, (c) exposure to $7 \%(\mathrm{v} / \mathrm{v})$ ethanol, (d) exposure to $5 \mu \mathrm{mol} \mathrm{Ca}^{2+}$ ionophore, A23187 I-1, (e) injection with $5 \mu \mathrm{mol}$ 1,4,5-inositoltrisphosphate $\left(\mathrm{IP}_{3}\right) \mathrm{I}^{-1}$, (f) exposure to 20 mmol caffeine $\mathrm{I}^{-1}$ and (g) exposure to $10 \mu \mathrm{mol}$ thapsigargin $\mathrm{I}^{-1}$. Data were expressed as variations of the relative fluorescence intensity. Top scale bar refers to (a) and the lower scale bar refers to (b-g). 
injection and quickly decreased up to the baseline value (Fig. 3f).

\section{Ion channel characterization}

Voltage-gated $\mathrm{K}^{+}$channel inhibitors, such as TEA and dendrotoxin, were ineffective in blocking the ion activation current and the hyperpolarization induced by the $\mathrm{Ca}^{2+}$ ionophore. Among the inhibitors of $\mathrm{Ca}^{2+}$-activated $\mathrm{K}^{+}$ channels, only incubation with rlberiotoxin at $100 \mathrm{nmol}$ $\mathrm{I}^{-1}$ for 2 min caused a complete inhibition in $27 \%$ of the immature oocytes and $34 \%$ in the matured oocytes, whereas a reduction of the peak amplitude was observed in $47 \%$ of the immature oocytes and $24 \%$ of the matured oocytes ( $n=12$ for both the stages). Pre-incubation of the oocytes with $\mathrm{Cl}^{-}$channels blockers, such as clorotoxin and DIDS, before the $\mathrm{Ca}^{2+}$ ionophore treatment, did not inhibit the electrical events.

\section{Discussion}

The interaction of the spermatozoon with the oocyte causes a series of physiological changes in the oocyte known as activation. The present study demonstrated that bovine oocytes matured in vitro that were exposed to spermatozoa undergo a bell-shaped outward ion current and hyperpolarization of the plasma membrane potential. Different substances acting as oocyte activators evoke similar electrical events, and in both immature and matured oocytes, these events are calcium dependent.

Modifications of the resting potential of the oocyte plasma membrane are described at fertilization in several mammalian species. In hamster and mouse oocytes, repetitive hyperpolarizing responses (Igusa et al., 1983) are described, whereas in rabbits, the spermatozoon causes a small depolarization of resting potential (McCulloh et al., 1983). In the human oocyte, hyperpolarization occurs as a unique, long lasting event (Gianaroli et al., 1994). Ion currents associated with the hyperpolarization have been recorded so far only in human oocytes (Gianaroli et al., 1994). This current showed similar peak amplitude with respect to the activation currents observed in bovine oocytes in the present study, but with a different time course (120 and 20 min in humans and cows, respectively). In the immature oocyte, the activation current showed a lower response compared with that of matured oocytes. This finding indicates that although sensitive to sperm action, the immature oocyte has not yet developed the necessary processes for fertilization. Moreover, the long duration of the ion activation current in the immature oocyte may be attributed to polyspermy due to the lack of cortical granule migration under the plasma membrane, a typical event of maturation (Hosoe and Shioya, 1997). This pattern has not been recorded in other species and highlights the difference between immature and matured oocytes.

The injection of a soluble sperm fraction into the immature and in vitro matured bovine oocytes triggered an outward current and hyperpolarization similar to that generated by the spermatozoon although with a shorter time course. Several authors (Dale et al., 1985; Stice and Robl, 1990; Homa and Swann, 1994; Wu et al., 1997; Lee et al., 2001; Okitsu et al., 2001) described activation events after the injection of either homologous or heterologous sperm extracts into oocytes of different species. Electrical currents elicited by sperm factor were only described in human oocytes showing differences in time course and peak amplitude compared with the sperm-induced ion current (Dale et al., 1996). Data from the present study are in agreement with this finding and show that sperm factor induces outward current for a shorter duration than at fertilization and with a higher peak amplitude. In addition, this finding further supports the hypothesis that a cytosolic sperm component is involved in triggering the activation events associated with fertilization in bovine oocytes, as described by Damiani et al. (1996). The higher electrical events induced by spermatozoa and sperm factor in matured oocytes indicates activation competence at maturation.

It is well known that oocyte activation may be induced by chemical substances (Tarkowski, 1975; Whittingham, 1980). Artificial stimuli cause a variety of electrical responses, indicating the presence of different mechanisms mobilized at activation (Eusebi and Siracusa, 1983). Bovine oocytes undergo embryo development up to the blastocyst stage after $\mathrm{Ca}^{2+}$ ionophore or ethanol treatment (Wang et al., 1999) with the same efficiency yielded by IVF (Boni et al., 2002). However, parthenogenetic embryos show different characteristics from IVF embryos (Winger et al., 1997) and fail to generate viable offspring (Fukui et al., 1992). In the present study, outward currents and hyperpolarization were also generated by treating oocytes with $\mathrm{Ca}^{2+}$ ionophore and ethanol. Although these substances activate the oocyte with a similar efficiency (Liu et al., 1998), they induce different electrical responses in immature and matured oocytes. In fact, matured oocytes were very sensitive to ethanol and generated an activation current and hyperpolarization significantly higher and with a PR shorter than in immature oocytes. The opposite pattern is found when $\mathrm{Ca}^{2+}$ ionophore as well as the other $\mathrm{Ca}^{2+}$ releasers were used. After exposure to spermatozoa, sperm factor and ethanol, the matured oocytes showed a higher reaction than immature oocytes, whereas the opposite has been recorded in the case of calcium releasers.

The increase in intracellular free calcium is universally recognized to be necessary for oocyte activation (Homa et al., 1993; Whitaker and Swann, 1993; Carroll et al., 1996). Single or repetitive calcium transients occur at fertilization in all species studied (Stricker, 1999). The fertilization current is calcium independent in tunicates (Dale, 1987) and calcium dependent in sea urchins (De Simone et al., 1998). In mammals, electrical activation events are due to $\mathrm{K}^{+}$conductance, which is dependent on calcium release in hamsters (Igusa and Miyazaki, 1983) and humans (Gianaroli et al., 1994), and calcium independent in mice (Igusa et al., 
1983). In the present study, all activators increased internal $\mathrm{Ca}^{2+}$. In addition, many similarities were found between the amplitudes of electrical currents and the dynamics of the increase in calcium either among the activators used or between mature and immature oocytes. However, comparison between these two dynamics is due to physiological (intracellular free-calcium mobilization versus membrane channel gating) and technical reasons such as buffering of calcium by the dye. In mammalian models, the ability of the oocyte to release $\mathrm{Ca}^{2+}$ after fertilization increases during maturation, which also occurs when calcium releasers are used (for a review, see Carroll et al., 1996). The first transient is of higher amplitude and is longer lasting in mature oocytes. In addition, the number of transients generated after oocyte activation markedly increases in mature oocytes. This increase is related to the increase of the intracellular calcium stores during maturation (Jones et al., 1995). In bovine oocytes, Boni et al. (2002) demonstrated that calcium stores decrease during maturation and are related to oocyte quality. In the present study, $\mathrm{Ca}^{2+}$ release after oocyte activation was demonstrated to be related to various activating stimuli rather than the store per se. This finding is consistent with the oocyte electrical response under the same stimulation. Different responses to activating stimuli may be attributed to the high selectivity of calcium releasers with respect to spermatozoa, sperm factor and ethanol, as these factors trigger higher but shorter responses. However, consistent with the results of the present study, in other species it has been shown that there is: (i) a higher electrical response to spermatozoa and sperm factor with respect to calcium releasers (Lee et al., 2001) and (ii) calcium releasers cannot induce repetitive oscillations, such as those triggered by spermatozoa and sperm factor (Carroll et al., 1994; Parrington et al., 1999).

In bovine oocytes, multiple calcium transients follow fertilization (Sun et al., 1994). The first transient was observed $4 \mathrm{~h}$ after insemination, a period necessary for penetration of the zona pellucida. The present study used zona pellucida-free matured oocytes and a marked shortening of gamete interaction time was observed, as an increase in calcium occurred $1 \mathrm{~min}$ after addition of spermatozoa and reached its maximum peak after $12 \mathrm{~min}$. In immature oocytes, an increase in calcium did not differ with respect to matured oocytes. The discrepancy between this finding and the results after the electrical stimulation may be attributed to: (i) the subsequent fusion of surplus spermatozoa due to removal of the zona pellucida causing repetitive calcium release and (ii) the dissociation constant $\left(\mathrm{K}_{\mathrm{d}}\right)$ of our fluorocrome which may have transformed repetitive sperm entry in a cumulative calcium response. Injection of sperm factor into oocytes has been shown to elicit repetitive $\mathrm{Ca}^{2+}$ increase in many mammalian species (Swann, 1990; Homa and Swann, 1994; Wu et al., 1997). In the present study, it was shown that injection of bovine sperm factor into bovine oocytes induces a $\mathrm{Ca}^{2+}$ increase in immature and matured oocytes with a pattern consistent with electrical currents. In addition, ethanol induced an increase in calcium, as already observed (Cuthbertson, 1983) in both mature and immature mouse oocytes with a pattern resembling electrical currents. Taken together, these data clearly indicate a relationship between calcium increase and electrical currents.

Preloading oocytes with EGTA inhibited the electrical events indicating calcium dependence of activation currents. $\mathrm{Ca}^{2+}$ releasers were tested to evaluate this dependence further. The use of $\mathrm{Ca}^{2+}$ ionophore and thapsigargin elicited either activation current and hyperpolarization or $\mathrm{Ca}^{2+}$ release; the dynamics of these events differed among activators and between immature and matured oocytes. The type of $\mathrm{Ca}^{2+}$ stores involved in oocyte activation mechanisms was characterized using $\mathrm{IP}_{3}$ and caffeine (Berridge, 1993). The use of these two $\mathrm{Ca}^{2+}$ releasers evoked a high response in terms of activation current and hyperpolarization, as well as $\mathrm{Ca}^{2+}$ release. It is noticeable that so far $\mathrm{IP}_{3}$-induced fertilization-like potential has been described in non-mammalian oocytes (Kline and Nuccitelli, 1985; Slack et al., 1986; Dale, 1988) and in human oocytes (Gianaroli et al., 1994). The present study describes for the first time that caffeine induces an ion activation current in mammalian oocytes.

Preloading oocytes with inhibitors of both receptors (heparin and procaine, respectively) abolished electrical responses, demonstrating the activity of both receptors in immature and in vitro matured oocytes. This finding is in agreement with results of Yue et al. (1995) who showed the independent action of $\mathrm{IP}_{3}$ and ryanodine receptors in matured bovine oocytes. In the present study, $\mathrm{IP}_{3}$ and caffeine evoked a higher response in terms of activation current and $\mathrm{Ca}^{2+}$ release in immature oocytes. This finding is in contrast to a study by Damiani et al. (1996) who showed the inability of bovine immature oocytes to respond to low $\mathrm{IP}_{3}$ dosages. It is difficult to explain the differences in the results, but as the present study used the same $I_{3}$ dosages ( 5 and $500 \mu_{\mathrm{mol}} \mathrm{I}^{-1}$ ) as those used by Damiani et al. (1996), it is likely that the oocyte quality chosen in the present study may have affected the results (Boni et al., 2002). In bovine oocytes, it has been demonstrated that $\mathrm{Ca}^{2+}$ increase at fertilization is an $\mathrm{IP}_{3}$ independent mechanism (Sun et al., 1994); however, results from the present study indicate that oocyte activation mechanisms cannot be attributed entirely to a single and known receptor pathway. In fact, heparin and procaine, injected separately into the oocyte, did not inhibit the $\mathrm{Ca}^{2+}$ ionophore-induced activation events. This finding indicates that $\mathrm{Ca}^{2+}$ ionophore activation is mediated by unspecific calcium release or by a pathway involving calcium release through ryanodine and $\mathrm{IP}_{3}$ receptor synergetic co-operation.

The origin of calcium mobilization in the oocyte differs among species (Igusa and Miyazaki, 1983; Kline and Kline, 1992; Wang et al., 1999). In bovine oocytes, a calcium influx through oocyte plasma membrane channels seems to be unnecessary for $\mathrm{Ca}^{2+}$ increase, as it does not differ in calcium-free medium. In addition, activation current and hyperpolarization do not differ under these conditions and 
this confirms their dependence by intracellular calcium mobilization. However, the inability to regenerate a second set of ionophore-induced ionic events after the activation currents supports the hypothesis that a desensitization or transient depletion of calcium stores affects their capacity to be activated by $\mathrm{Ca}^{2+}$ ionophore.

A common characteristic of the activation current in most of the experiments performed was an initial inward current which corresponded to a small depolarization. The use of $\mathrm{Ca}^{2+}$-free medium abolished the initial inward current without affecting the subsequent activation current dynamics. This finding indicates that the electrical events at oocyte activation begin with an initial external calcium entry. The higher values found in immature oocytes further sustain this hypothesis on the basis of our previous study demonstrating a prevalence of plasma membrane calcium currents in immature oocytes (Tosti et al., 2000). Finally, the role of this first calcium entry does not seem crucial for oocyte activation as the oocyte is also activated in $\mathrm{Ca}^{2+}$-free medium.

The activation current and hyperpolarization observed in the present study indicate the involvement of $\mathrm{K}^{+}$channels in oocyte activation. In a previous study, it was found that $\mathrm{K}^{+}$ permeability in the bovine oocyte was high at the meiotic block stages, that is, in immature and matured oocytes (Tosti et al., 2000). Both the fertilization potential and fertilization current have been related to $\mathrm{Ca}^{2+}$-activated $\mathrm{K}^{+}$ currents in hamsters and humans (Miyazaki and Igusa, 1982; Dale et al., 1996). $\mathrm{Ca}^{2+}$-activated $\mathrm{K}^{+}$channels are ubiquitary of different conductance channels (Latorre et al., 1989). They are known to link membrane excitability and cell metabolism (Behrens et al., 1988; Latorre et al., 1989). On the basis of the calcium dependence of activation currents in the present study, several inhibitors of both $\mathrm{K}^{+}$- and $\mathrm{Ca}^{2+}$-activated $\mathrm{K}^{+}$channels were screened and activation current and hyperpolarization were inhibited only by rlberiotoxin, a specific blocker of high conductance $\mathrm{Ca}^{2+}$-activated $\mathrm{K}^{+}$channels (Candia et al., 1992). In addition, a possible role of $\mathrm{Ca}^{2+}$-activated $\mathrm{Cl}^{-}$channels that are involved in the activation current of amphibians (Jaffe and Schlichter, 1985; Kline and Nuccitelli, 1985) and mammals (Eusebi and Siracusa, 1983) was excluded. On this basis, the first electrical event in bovine oocyte activation appears to be the gating of $\mathrm{Ca}^{2+}$-activated $\mathrm{K}^{+}$channels. This finding may also explain why in matured oocytes ethanol induced activation events in a similar way to spermatozoa and sperm factor, as ethanol increases the activity of large conductance $\mathrm{Ca}^{2+}$-activated $\mathrm{K}^{+}$channels (Dopico et al., 1996).

In conclusion, the present study has shown that fertilization and parthenogenetic activation in bovine oocytes elicit plasma membrane outward currents and hyperpolarization of membrane potential. Both of these events are dependent on internal calcium release and are mediated by high conductance $\mathrm{Ca}^{2+}$-activated $\mathrm{K}^{+}$channels. $\mathrm{IP}_{3}$ and ryanodine receptors are active in both the immature and in vitro matured oocytes, but none of these factors is responsible for the activation current. Immature oocytes are sensitive to all activators used, showing different responses with respect to matured oocytes. In vitro matured oocytes showed a higher electrical and calcium response after exposure to spermatozoa, sperm factor and ethanol compared with immature oocytes but a lower response to calcium releasers. This finding indicates that during maturation the oocyte acquires the competence to react to different activation stimuli with different dynamics.

The authors thank K. Swann and A. lanora for helpful comments and critical revision of the manuscript. The authors extend their thanks to S. Gentile for useful advices and G. Gargiulo for assistance with computer graphics.

\section{References}

Behrens MI, Vergara R and Latorre R (1988) Calcium activated potassium channels of large unitary conductance Brazilian Journal of Medical Biological Research 21 1101-1117

Berridge MJ (1993) A tale of two messengers Nature 365 388-389

Boni R, Cuomo A and Tosti E (2002) Developmental potential in bovine oocytes is related to cumulus-oocyte complex (COC) grade, calcium current activity and calcium stores Biology of Reproduction 66 836-842

Busa WB and Nuccitelli R (1985) An elevated free cytosolic $\mathrm{Ca}^{2+}$ wave follows fertilization in eggs of the frog Xenopus laevis. Journal of Cell Biology 100 1325-1329

Candia S, Garcia ML and Latorre R (1992) Mode of action of iberiotoxin a potent blocker of the large conductance $\mathrm{Ca}^{2+}$-activated $\mathrm{K}^{+}$channels Biophysical Journal 65 583-590

Carroll J, Swann K, Whittingham DG and Whitaker M (1994) Spatiotemporal dynamics of intracellular $\left[\mathrm{Ca}^{2+}\right]_{i}$ oscillations during the growth and meiotic maturation of mouse oocytes Development 120 3507-3517

Carroll J, Jones KT and Whittingham DG (1996) $\mathrm{Ca}^{2+}$ release and the development of $\mathrm{Ca}^{2+}$ release mechanisms during oocyte maturation: a prelude to fertilization Reviews of Reproduction 1 137-143

Clapham DE (1995) Calcium signalling Cell 80 259-268

Collas P, Fissore R, Robl JM, Sullivan EJ and Barnes FL (1993) Electrically induced calcium elevation, activation and parthenogenetic development of bovine oocytes Molecular Reproduction and Development 34 $212-223$

Cuthbertson KSR (1983) Parthenogenetical activation of mouse oocytes in vitro with ethanol and benzyl alcohol Journal of Experimental Zoology $226311-314$

Dale B (1987) Fertilization channels in ascidian eggs are not activated by calcium Experimental Cell Research 172 474-480

Dale B (1988) Primary and secondary messengers in the activation of ascidian eggs Experimental Cell Research 177 205-211

Dale B (1994) Oocyte activation in invertebrates and humans Zygote 2 373-377

Dale B and De Felice LJ (1984) Sperm activated channels in ascidian oocytes Developmental Biology 121 235-239

Dale B, De Felice LJ and Ehrenstein G (1985) Injection of a soluble sperm extract into sea urchin eggs triggers the cortical reaction Experientia $\mathbf{4 1}$ 1068-1070

Dale B, Fortunato A, Monfrecola V and Tosti E (1996) A soluble sperm factor gates $\mathrm{Ca}^{2+}$-activated $\mathrm{K}^{+}$channels in human oocytes Journal of Assisted Reproduction and Genetics 13 573-577

Damiani P, Fissore RA, Cibelli JB, Long CR, Balise JJ, Robl JM and Duby RT (1996) Evaluation of developmental competence and ooplasmic maturation of calf oocytes Molecular Reproduction and Development 45 521-534

De Loos F, van Vliet F, van Maurik P and Kruip TAM (1989) Morphology of immature bovine oocytes Gamete Research 24 197-204

De Simone ML, Grumetto L, Tosti E, Wilding M and Dale B (1998) Nonspecific currents at fertilisation in sea urchin oocytes Zygote 6 11-15 
Dopico AM, Lemos JR and Treistman SN (1996) Ethanol increases the activity of large conductance, $\mathrm{Ca}\left({ }^{2+}\right)$-activated $\mathrm{K}^{+}$channels in isolated neurohypophysial terminals Molecular Pharmacology 49 40-48

Eusebi F and Siracusa G (1983) An electrophysiological study of parthenogenetic activation in mammalian oocytes Developmental Biology 96 386-395

Fukui Y, Sawai K, Furudate M, Sato N, Iwazami Y and Ohasaki K (1992) Parthenogenetic development of bovine oocytes treated with ethanol and cytochalasin B after in vitro maturation Molecular Reproduction and Development 33 357-362

Gianaroli L, Tosti E, Magli MC, laccarino M and Ferraretti AP (1994) Fertilization current in human oocytes Molecular Reproduction and Development 38 209-214

Gillot I and Whitaker M (1993) Imaging calcium waves in eggs and embryos Journal of Experimental Biology $184213-219$

Hosoe M and Shioya Y (1997) Distribution of cortical granules in bovine oocytes classified by cumulus complex Zygote 5 371-376

Homa ST and Swann K (1994) A cytosolic sperm factor triggers calcium oscillation and hyperpolarization in human oocytes Human Reproduction 9 2356-2361

Homa ST, Carroll J and Swann K (1993) The role of calcium in mammalian oocyte maturation and egg activation Human Reproduction 8 1274-1281

Kline D and Kline JT (1992) Repetitive calcium transients and the role of calcium in exocytosis and cell cycle activation in the mouse egg Developmental Biology 149 80-89

Kline D and Nuccitelli R (1985) The wave of activation current in the Xenopus egg Developmental Biology $111471-487$

Igusa Y and Miyazaki S (1983) Effects of altered extracellular and intracellular calcium concentration on hyperpolarizing responses of the hamster egg Journal of Physiology (London) 340 611-632

Igusa Y, Miyazaki S and lamashita N (1983) Periodic hyperpolarization responses in hamster and mouse eggs fertilized with mouse sperm Journal of Physiology (London) 340 633-647

Jaffe LA and Schlichter LC (1985) Fertilization-induced ionic conductances in eggs of the frog, Rana pipiens. Journal of Physiology (London) 358 299-319

Jones KT, Carroll J and Whittingham DG (1995) Ionomycin, thapsigargin, ryanodine and sperm induced $\mathrm{Ca}^{2+}$ release increase during meiotic maturation in mouse oocytes Journal of Biological Chemistry $\mathbf{2 7 0}$ 6671-6677

Latorre R, Oberhauser A, Labarca P and Alvarez O (1989) Varieties of calcium-activated potassium channels Annual Reviews of Physiology $5 \mathbf{1}$ 385-399

Lee SC, Fissore RA and Nuccitelli R (2001) Sperm factor initiates capacitance and conductance changes in mouse eggs that are more similar to fertilization than IP3- or $\mathrm{Ca}^{2+}$-induced changes Developmental Biology 232 127-148

Liu L, Ju JC and Yang X (1998) Parthenogenetic development and protein patterns of newly matured bovine oocytes after chemical activation Molecular Reproduction and Development 49 298-307

McCulloh DH, Rexroad CE, Jr and Levitan H (1983) Insemination of rabbit eggs is associated with slow depolarisation and repetitive diphasic membrane potentials Developmental Biology 95 372-377

Miyazaki SI (1988) Fertilization potential and calcium transients in mammalian eggs Development, Growth and Differentiation 30 603-610

Miyazaki S and Igusa Y (1982) $\mathrm{Ca}^{2+}$-mediated activation of a $\mathrm{K}^{+}$current at fertilization of golden hamster eggs Proceedings National Academy of Sciences USA 79 931-935

Nagai T (1987) Parthenogenetic activation of cattle follicular oocytes in vitro with ethanol Gamete Research 16 243-249

Nuccitelli R (1980) The electrical changes accompanying fertilization and cortical vesicle secretion in the Medaka egg Developmental Biology $\mathbf{7 6}$ 483-498

Okitsu O, Yamano S and Aono T (2001) Activation of bovine oocytes matured in vitro by injection of bovine and human spermatozoa or their cytosolic fractions Zygote 9 89-95

Parrington J, Jones KT, Lai A and Swann K (1999) The soluble sperm factor that causes $\mathrm{Ca}^{2+}$ release from sea-urchin (Lytechinus pictus) egg homogenates also triggers $\mathrm{Ca}^{2+}$ oscillation after injection into mouse eggs Biochemical Journal 341 1-4

Parrish JJ, Susko-Parrish JL, Liebfried-Ruthledge ML, Critser ES, Eyestone WH and First NL (1986) Bovine in vitro fertilization with frozen-thawed semen Theriogenology 25 591-600

Parrish JJ, Kim CL and Bae IH (1992) Current concepts of cell cycle regulation and its relationship to oocyte maturation, fertilization and embryo development Theriogenology 38 277-296

Patel R, Wright E and Whitaker M (1997) Caffeine overrides the S-phase cell cycle block in sea urchin embryos Zygote 5 127-138

Petr J, Rozinek J, Jilek F and Urbankova D (2000) Activation of porcine oocytes using cyclopiazonic acid, an inhibitor of calcium-dependent ATPases Journal of Experimental Zoology 287 304-315

Presicce G and Yang X (1994) Parthenogenetic development of bovine oocytes matured in vitro for $24 \mathrm{hrs}$ and activated by ethanol and cycloeximide Molecular Reproduction and Development 38 380-385

Russo GL, Kyozuka K, Antonazzo L, Tosti E and Dale B (1996) Maturation promoting factor in ascidian oocytes is regulated by different intracellular signals at meiosis I and II Development 122 1995-2003

SAS/STAT User's Guide Release 6.03 Edn. Cary, NC: Statistical Analysis System Institute, Inc.; 1988

Schlichter LC and Elisson RP (1981) Electrical responses of immature and mature Rana pipiens oocytes to sperm and other activating stimuli Developmental Biology 83 33-41

Shi Z, Jiang S and Yang X (1993) Synergistic effect of A23187 and cycloheximide allows effective activation of freshly matured bovine oocytes Theriogenology 38309 (Abstract)

Slack BE, Bell JE and Benos DJ (1986) Inositol-1,4,5-trisphosphate injection mimics fertilization potentials in sea urchin eggs American Journal of Physiology Cell Physiology 250 C340-344

Steinhardt RA and Epel D (1974) Activation of sea urchin eggs by a calcium ionophore Proceedings National Academy of Sciences USA 71 1915-1919

Steinhardt RA, Epel D, Carrol EJ and Yanagimachi R (1974) Is calcium ionophore a universal activator for unfertilised eggs? Nature (London) $25241-43$

Stice SL and Robl JM (1990) Activation of mammalian oocytes by a factor obtained from rabbit sperm Molecular Reproduction and Development 25 272-280

Stricker SA (1999) Comparative biology of calcium signalling during fertilization and egg activation in animals Developmental Biology 211 157-176

Sun FZ, Bradshaw JP, Galli C and Moor RM (1994) Changes in calcium concentration in bovine oocytes following penetration by spermatozoa Journal of Reproduction and Fertility $101713-719$

Swann K (1990) A cytosolic sperm factor stimulates repetitive calcium increase and mimics fertilization in hamster oocytes Development 110 1295-1302

Swann K and Ozil JP (1994) Dynamics of the calcium signal that triggers mammalian egg activation International Reviews of Cytolology 152 183-222

Swann K and Parrington J (1999) Mechanism of Ca ${ }^{2+}$ release at fertilization in mammals Journal of Experimental Zoology 285 267-275

Tarkowski AK (1975) Induced parthenogenesis in the mouse Symposium of the Society of Developmental Biology 33 107-129

Tosti E, Boni R and Cuomo A (2000) $\mathrm{Ca}^{2+}$ current activity decreases during meiotic progression in bovine oocytes American Journal of Physiology Cell Physiology 279 1795-1800

Yoshida M, Sensui N, Inoue I, Morisawa M and Mikoshiba R (1998) Role of two series of $\mathrm{Ca}^{2+}$ oscillations in activation of ascidian eggs Developmental Biology 203 122-133

Yue C, White KL, Reed WA and Bunch TD (1995) The existence of inositol 1,4,5-trisphosphate and ryanodine receptors in mature bovine oocytes Development 121 2645-2654

Wang WH, Machaty Z, Ruddock N, Abeydeera LR, Boquest AC, Prather RS and Day BN (1999) Activation of porcine oocytes with calcium ionophore: effects of extracellular calcium Molecular Reproduction and Development 53 99-107 
Whitaker M and Swann K (1993) Lighting the fuse at fertilization Development 117 1-12

Whittingham DG (1980) Parthenogenesis in mammals. In: Oxford Reviews of Reproductive Biology 2 pp 205-231 Ed. CA Finn. Oxford University Press

Winger QA, De La Fuente R, King WA, Armstrong DT and Watson AJ (1997) Bovine parthenogenesis is characterized by abnormal chromosomal complements: implications for maternal and paternal codependence during early bovine development Developmental Genetics 21 160-166
Wu HW, He CL and Fissore R (1997) Injection of a porcine sperm factor triggers calcium oscillations in mouse oocytes and bovine eggs Molecular Reproduction and Development 46 176-189

Received 20 May 2002

First decision 7 August 2002.

Revised manuscript received 3 September 2002

Accepted 4 September 2002. 